\title{
STOICHIOMETRY: LINKING ELEMENTS TO BIOCHEMICALS
}

\author{
Thomas R. Anderson,,${ }^{1,4}$ MaArten Boersma, ${ }^{2}$ And David Raubenheimer ${ }^{3,5}$ \\ ${ }^{1}$ Southampton Oceanography Centre, Waterfront Campus, European Way, Southampton SO14 3ZH, UK \\ ${ }^{2}$ Alfred Wegener Institute for Polar and Marine Research, Biologische Anstalt Helgoland, Postfach 180, 27483 Helgoland, \\ Germany, and Max-Planck-Institut für Limnologie, Postfach 165, 24302 Plön, Germany \\ ${ }^{3}$ Department of Zoology, Oxford University, South Parks Road, Oxford OX1 3PS, UK
}

\begin{abstract}
Ecological stoichiometry is a useful tool for studying how the elemental composition of organisms and their food affects production, nutrient cycling, and foodweb dynamics. Two analyses are presented here that show that the use of simple element ratios in stoichiometric calculations may in certain circumstances prove inadequate because of the influence in animal nutrition of biochemical aspects of diet. In the first, a stoichiometric analysis of herbivores consuming food with varying carbon to nitrogen $(\mathrm{C}: \mathrm{N})$ ratios is undertaken, in which the intake of $\mathrm{C}$ is segregated into easily assimilated compounds and fiber. Two herbivore strategies emerge from the analysis, both as a means of minimizing limitation by $\mathrm{C}$, not $\mathrm{N}$ : fiber eaters that consume high $\mathrm{C}: \mathrm{N}$ food and have efficient fiber digestion, and selective feeders that consume low $\mathrm{C}: \mathrm{N}$ food but that do not possess fiberdigesting enzymes. In the second example, the stoichiometric axiom that a single substrate, the one in least supply relative to demand, limits growth is used to identify potentially limiting essential amino acids in the diets of a range of animals. Large consumer-prey imbalances in amino acids were found in several cases, indicating that, at least in theory, growth should be strongly limited by individual amino acids rather than bulk N. In practice such limitation may be offset in consumers by physiological and other factors such as symbiotic relationships. The two analyses emphasize the simplicity of element stoichiometry, highlighting the need to consider biochemical and physiological arguments when undertaking stoichiometric studies of carbon and nutrient transfers in ecosystems.
\end{abstract}

Key words: $\quad$ amino acids; $C: N$ ratios in food; growth limitation; nitrogen limitation; nutrient cycling; stoichiometry.

\section{INTRODUCTION}

Elements cannot be synthesized or interconverted by organisms, and must therefore be obtained in the diet in quantities sufficient to meet requirements for growth and respiration. Frequently, foods do not contain elements in ratios ideal to the consumer, to the extent that animals are thought to be limited by nitrogen $(\mathrm{N})$ in many terrestrial and marine environments (Roman 1983, White 1993) and phosphorus (P) in freshwater systems (DeMott and Gulati 1999). There are two main lines of supporting evidence: correlative studies relating growth to intake (e.g., White 1984, Plath and Boersma 2001), and stoichiometric studies. The latter involve comparing element ratios in consumers (the demand ratio) and their prey (the supply ratio) and, taking into consideration utilization efficiencies, defining the limiting element as the one in least supply relative to demand. These utilization efficiencies can be written as "transfer functions" that describe the time-integrated passage of nutrients through animals (Raubenheimer

Manuscript received 26 April 2002; revised 4 June 2003; accepted 27 July 2003. Corresponding Editor: R. M. Nisbet. For reprints of this Special Feature, see footnote 1, p. 1177.

${ }^{4}$ E-mail: tra@soc.soton.ac.uk

5 Present address: School of Biological Sciences and Psychology Department, University of Auckland, Private Bag 92019 Auckland, New Zealand. and Simpson 1998). Theory predicts that in circumstances where nutrients are limiting to growth and performance, organisms should develop transfer functions that favor efficient retention of nutrients in short supply, whereas rates of gain should be maximized when animals are time limited. Various specialized morphological and physiological adaptations, including symbiotic associations, may be involved in optimizing the gain of limiting nutrients (Raubenheimer and Simpson 1998).

Stoichiometric studies of element transfer operate by assuming that limiting elements are used as efficiently as possible for growth, with excesses of nonlimiting nutrients remaining unutilized. Hence it is essential to understand what the maximum potential growth efficiencies are for different elements and animals. The theoretical maximum for carbon (C) is $\sim 80 \%$ (Schroeder 1981), although the real maximum for an animal in its natural environment may be significantly less due to additional energy costs such as thermoregulation. Whereas $\mathrm{C}$ is required for both new biomass and energy, nutrient elements fulfil primarily a structural role. So, for example, if C-rich substrates such as carbohydrates and lipids are preferentially utilized to meet catabolic costs, then $\mathrm{N}$-rich compounds such as proteins can be spared, allowing greater growth and reproduction. Thus the proportion of catabolic demand

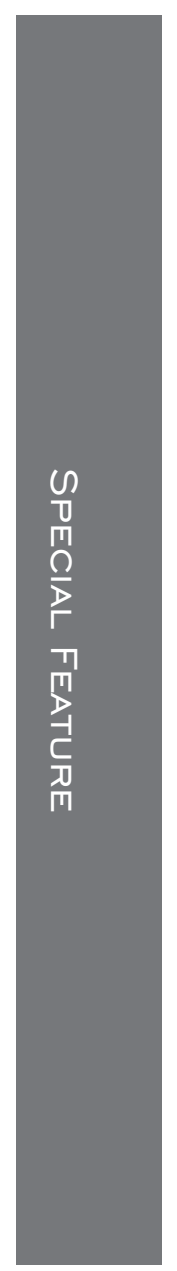


that has to be met using nitrogenous substrates should theoretically decline as $\mathrm{N}$ concentrations in foods decrease, as has been observed in caterpillars (Thompson 1998) and locusts (Raubenheimer and Simpson 2003). Indeed a point is reached where, at least in theory, $\mathrm{N}$ is utilized for production with $100 \%$ efficiency (Anderson 1992, Urabe and Watanabe 1992). Whereas locusts fed synthetic foods that are nitrogen limiting approach this limit (Zanotto et al. 1993), for most animals the experimental evidence to back up an assumption of high utilization efficiencies under nutrient-limiting conditions is weak. Marine copepods use $\mathrm{N}$ for egg production with an efficiency of only $40 \%$ even when supplied with high C:N food (Kiørboe 1989). Similarly low growth efficiencies were recorded for larvae of the cabbage butterfly Pieris rapae reared on leaves of different food plants (Slansky and Fleeny 1977). These low utilization efficiencies for apparently limiting nutrients may be a result of biochemical, rather than elemental, constraints on production.

Biochemical constraints on growth fall broadly into two main categories: (1) "macronutrients" associated with bulk properties, i.e., proteins, lipids, carbohydrates, etc., and (2) "micronutrients" related to specific compounds such as individual fatty or amino acids. In this paper we show how element stoichiometric theory can be extended to include biochemical features of the food and consumer using two examples, one each for macro- and micronutrients. In the first example we show that the proportion of food $\mathrm{C}$ in fibrous materials such as cellulose may have important consequences for the stoichiometric analysis of $\mathrm{C}$ vs. $\mathrm{N}$ limitation in herbivores. In the second, the potential for imbalances of amino acids to override limitation by bulk $\mathrm{N}$ is examined in a range of animals. The analyses presented are not intended to provide definitive outcomes of the chosen scenarios. Rather they demonstrate that biochemical arguments can have important impacts on growth efficiencies and should therefore be taken into consideration when undertaking stoichiometric analyses of flows and sequestration of $\mathrm{C}$ in food webs.

\section{Macronutrient StOICHIOMETRY}

Many animals preferentially ingest low $\mathrm{C}: \mathrm{N}$ food, which suggests that they are maximizing $\mathrm{N}$ intake in response to limitation by that element. Yet much of the $\mathrm{C}$ present in foodstuffs is often present in forms not readily available to consumers. Complex polysaccharides such as cellulose, hemicellulose and lignin (fiber) are important structural components of plants that require extensive digestion if animals are to utilize the associated $\mathrm{C}$ for growth and respiration. In contrast, labile compounds are readily assimilated by organisms. For example, soluble carbohydrates are digested and absorbed by locusts with very high efficiency, with excesses over requirements being voided by respiration (Zanotto et al. 1997). In the event of a shortage of simple sugars in the pool of assimilated labile com- pounds, animals may use other labile substrates for gluconeogenesis (Thompson 1998), which will result in deamination of amino acids if these compounds contain N. So is it possible that the refractory nature of C in fibrous diets could lead to $\mathrm{C}$ limitation in animals? Here we compare two stoichiometric analyses of herbivore production in response to food $\mathrm{C}: \mathrm{N}$. The first is a simple element analysis of bulk food $\mathrm{C}: \mathrm{N}$, which is then compared with an analysis that differentiates fibrous $\mathrm{C}$ from other more readily utilizable $\mathrm{C}$ in the diet.

Consider an animal with a $\mathrm{C}: \mathrm{N}$ ratio in biomass of $\theta_{\mathrm{Z}}$ ingesting a food item with $\mathrm{C}: \mathrm{N} \theta_{\mathrm{f}}$. The nomenclature we use follows on from previous studies that have considered zooplankton (Z) consuming food (f), e.g., Anderson and Hessen (1995). The gross growth efficiencies (GGEs) for $\mathrm{C}$ and $\mathrm{N}, \mathrm{K}_{\mathrm{C}}$ and $\mathrm{K}_{\mathrm{N}}$ (the efficiencies of conversion of ingested food into new biomass), depend on the balance of substrates in the diet and the demands of the consumer. Stoichiometric theory dictates that the limiting element is utilized with its theoretical maximum GGE, which we define as the "limiting growth efficiency" (LGE), $K^{*}$. Thus if $\mathrm{N}$ is limiting, $K_{\mathrm{N}}=K_{\mathrm{N}}^{*}$, and $K_{\mathrm{C}}<K_{\mathrm{C}}^{*}$ due to the presence of excess $\mathrm{C}$ in the diet. Carbon will limit growth if the supply of $\mathrm{C}\left(\theta_{\mathrm{f}}\right)$ relative to demand $\left(\theta_{\mathrm{Z}} / K_{\mathrm{C}}^{*}\right)$ is less than that of $\mathrm{N}$ (supply 1 , demand $1 / K_{\mathrm{N}}^{*}$ ), i.e., $K_{\mathrm{C}}^{*} \theta_{\mathrm{f}}<K_{\mathrm{N}}^{*} \theta_{\mathrm{Z}}$, otherwise $\mathrm{N}$ limits. A threshold elemental ratio, $\theta_{\mathrm{f}}^{*}$ defines the transition point between the two modes of limitation:

$$
\theta_{\mathrm{f}}^{*}=\frac{K_{\mathrm{N}}^{*} \theta_{\mathrm{Z}}}{K_{\mathrm{C}}^{*}} .
$$

Realized GGEs for $\mathrm{C}$ and $\mathrm{N}$, depending on mode of limitation, are then

$$
\begin{array}{lll}
\text { C limitation: } & K_{\mathrm{C}}=K_{\mathrm{C}}^{*} & K_{\mathrm{N}}=K_{\mathrm{C}}^{*}\left(\theta_{\mathrm{f}} / \theta_{\mathrm{Z}}\right) \\
\text { N limitation: } & K_{\mathrm{N}}=K_{\mathrm{N}}^{*} & K_{\mathrm{C}}=K_{\mathrm{N}}^{*}\left(\theta_{\mathrm{Z}} / \theta_{\mathrm{f}}\right) .
\end{array}
$$

If, when limiting, assimilated (non-egested) $\mathrm{C}$ can potentially be used for growth with net production efficiency (fraction assimilated $\mathrm{C}$ allocated to new biomass) $k_{\mathrm{C}}^{*}$ and assimilated $\mathrm{N}$ with a potential net production efficiency of 1.0, and $\mathrm{C}$ and $\mathrm{N}$ are assimilated with efficiencies $A_{\mathrm{C}}, A_{\mathrm{N}}$ (irrespective of what element is limiting in the diet), then $K_{\mathrm{C}}^{*}$ and $K_{\mathrm{N}}^{*}$ are $k_{\mathrm{C}}^{*} A_{\mathrm{C}}$ and $A_{\mathrm{N}}$, respectively. Predicted realized C gross growth efficiency, $K_{\mathrm{C}}$ (Eqs. 1-3), for animals consuming a constant $\mathrm{C}$ ration, for different values of $\mathrm{C}$ assimilation efficiency $\left(A_{\mathrm{C}}\right)$, is shown in Fig. 1. Two planes are evident. The smaller one (high $A_{\mathrm{C}}$, high $\theta_{\mathrm{f}}$ ) marks Nlimited parameter space. Production (proportional to $K_{\mathrm{C}}$ ) is uninfluenced by the efficiency with which food $\mathrm{C}$ is assimilated $\left(A_{\mathrm{C}}\right)$, but can be maximized by selecting food with high $\mathrm{N}$ content (low $\mathrm{C}: \mathrm{N}$ ). The other plane represents $\mathrm{C}$-limited parameter space. Predicted growth is now responsive to increasing $\mathrm{C}$ assimilation, 


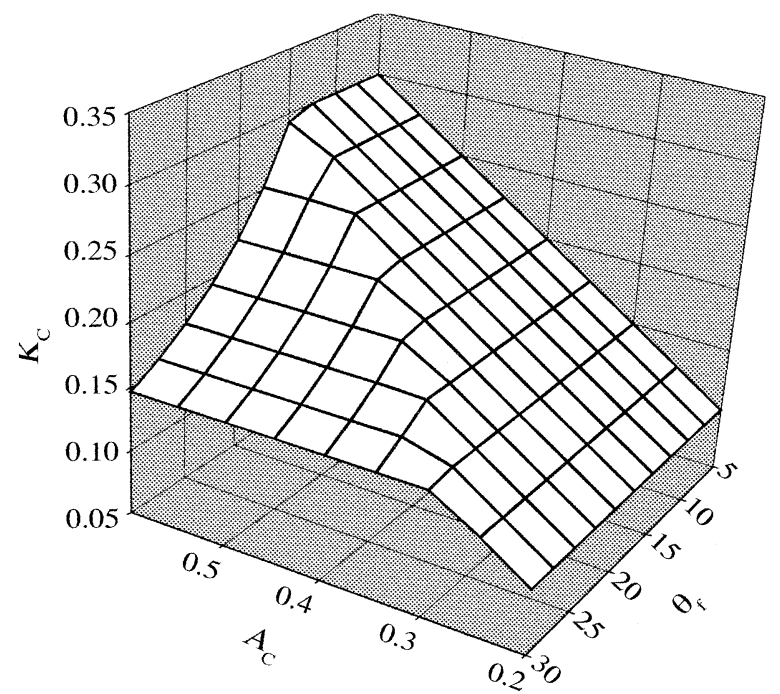

FIG. 1. Elemental stoichiometry. Calculated carbon gross growth efficiency $\left(K_{\mathrm{C}}\right)$ for animals ingesting a constant C ration, food C:N $\left(\theta_{\mathrm{f}}\right)=5-30$, and carbon assimilation efficiency $\left(A_{\mathrm{C}}\right)=0.2-0.6$ (Eqs. $\left.1-3\right)$. Other parameter settings: $\mathrm{C}$ net production efficiency $\left(k_{\mathrm{C}}^{*}\right)=0.5, \mathrm{~N}$ assimilation efficiency $\left(A_{\mathrm{N}}\right)=0.8$, consumer $\mathrm{C}: \mathrm{N}$ biomass ratio $\left(\theta_{\mathrm{Z}}\right)=5.5$.

but there is no benefit in animals selecting high or low $\mathrm{C}: \mathrm{N}$ food.

Moving on to our second part of the analysis, we note that the foregoing elemental stoichiometric analysis is simplistic in that in reality $\mathrm{C}$ and $\mathrm{N}$ are not assimilated independently of each other, but as compounds. Plant $\mathrm{C}$ can be divided among several fractions: organic N compounds, lipid, soluble sugars, organic acids, lignin, and (hemi)cellulose. The first four can be considered to be labile, i.e., readily assimilated and utilized by grazers, whereas the structural nature of lignin and cellulose makes them resistant to use. We now assume that plant material is split between labile and structural compounds with associated assimilation efficiencies $A_{\mathrm{L}}$ and $A_{\mathrm{S}}$, labile compounds have a fixed $\mathrm{C}: \mathrm{N}, \theta_{\mathrm{L}}$, and that there is no $\mathrm{N}$ in the structural fraction. If organic $\mathrm{N}$ compounds have a $\mathrm{C}: \mathrm{N}$ of 3.96 (Anderson 1992 ) and are $65 \%$ of the total labile $C$ in leaves (based on tabulated fractions in Poorter and Bergkotte [1992] and van Arendonk and Poorter [1994], using C content for each fraction as in Niemann et al. [1992]), then a characteristic value for $\theta_{\mathrm{L}}$ is $3.96 / 0.65=6.1$. Typical combined cellulose and lignin contents of foliar material are around 40-60\% (Taylor et al. 1989), causing high $\mathrm{C}: \mathrm{N}$ relative to, for example, aquatic algae. In our analysis, $\mathrm{C}$ over and above the labile fraction is considered to be fiber. As before we assume that $\mathrm{C}$ and $\mathrm{N}$ can potentially be used post-assimilation with net production efficiencies $k_{\mathrm{C}}^{*}$ and 1.0 , in which case $K_{\mathrm{N}}^{*}$ equals $A_{\mathrm{L}}$, and $K_{\mathrm{C}}^{*}$ depends on the relative proportions of fibrous and non-fibrous $\mathrm{C}$ present:

$$
K_{\mathrm{C}}^{*}=k_{\mathrm{C}}^{*} \frac{A_{\mathrm{L}} \theta_{\mathrm{L}}+A_{\mathrm{S}}\left(\theta_{\mathrm{f}}-\theta_{\mathrm{L}}\right)}{\theta_{\mathrm{f}}}
$$

Predicted $K_{\mathrm{C}}$ (Eqs. 1-4) for fiber assimilation efficiency $\left(A_{\mathrm{S}}\right)=0.2-0.6$, food C:N-5-30, and potential C net production efficiency $\left(k_{\mathrm{C}}^{*}\right)=0.5$ or 0.2 is shown in Fig. 2 . When assimilated $\mathrm{C}$ is used relatively efficiently $\left(k_{\mathrm{C}}^{*}\right.$ $=0.5$ ) for growth (Fig. 2a), a region of N-limited parameter space is observed similar in shape to that found in the simple element analysis (Fig. 1). In this region predicted growth is unaffected by the assimilation efficiency assigned to cellulose $\left(A_{\mathrm{S}}\right)$, indicating that $\mathrm{N}$ limited animals ingesting highly fibrous diets should

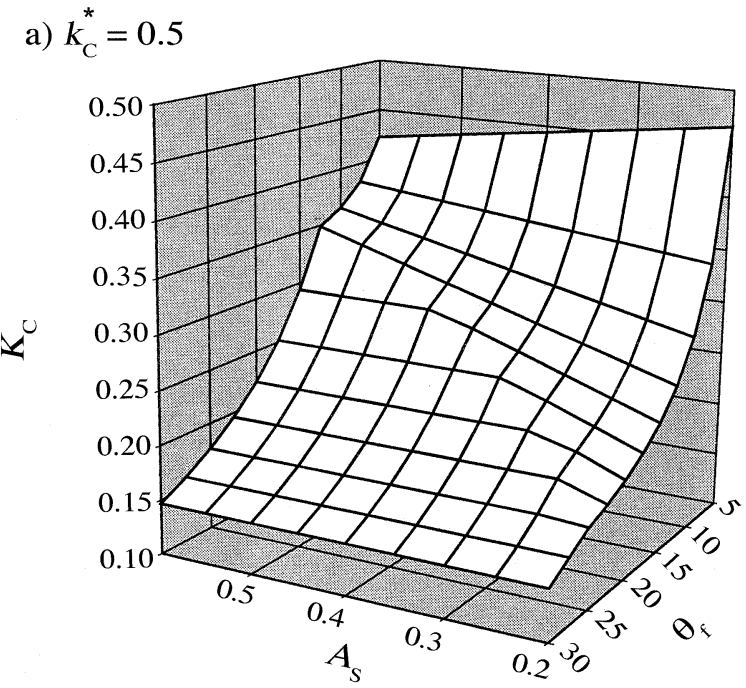

b) $k_{\mathrm{C}}^{*}=0.2$

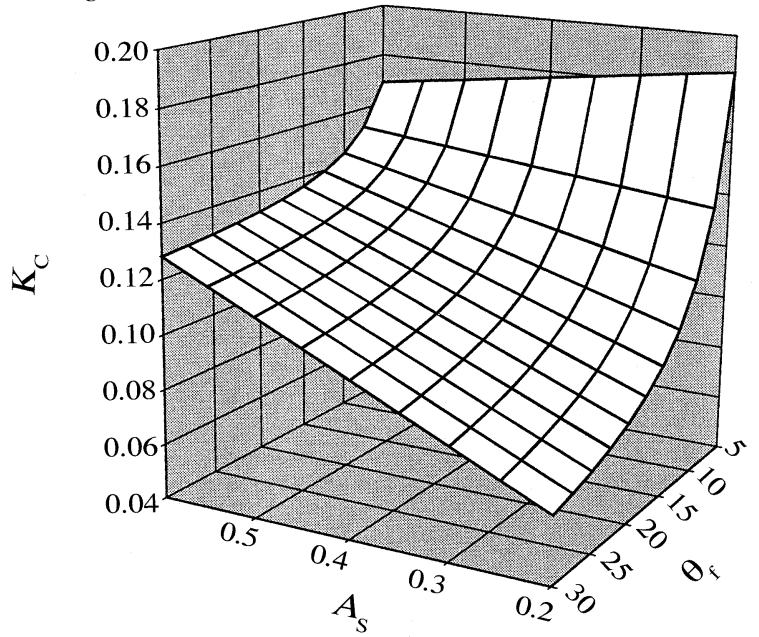

FIG. 2. Macronutrient stoichiometry. Calculated carbon gross growth efficiency $\left(K_{\mathrm{C}}\right)$ for animals ingesting a constant C ration, food C:N $\left(\theta_{\mathrm{f}}\right)=5-30$, and assimilation of fiber $\mathrm{C}$ $\left(A_{\mathrm{S}}\right)=0.2-0.6$ (Eqs. 1-4): (a) $\mathrm{C}$ net production efficiency $\left(k_{\mathrm{C}}^{*}\right)=0.5$, (b) $k_{\mathrm{C}}^{*}=0.2$. Other parameter settings: assimilation efficiency labile substrates $\left(A_{\mathrm{L}}\right)=0.8, \mathrm{C}: \mathrm{N}$ ratio of labile substrates $\left(\theta_{\mathrm{L}}\right)=6.1$, consumer $\mathrm{C}: \mathrm{N}$ biomass ratio $\left(\theta_{\mathrm{Z}}\right)$ $=5.5$. 
gain no benefit from investing heavily in fiber-digesting enzymes. However, predicted $K_{\mathrm{C}}$ under C-limiting conditions contrasts markedly with that of the element analysis. It is no longer independent of food $\mathrm{C}: \mathrm{N}$, but increases at low $\mathrm{C}: \mathrm{N}$, caused by the greater average $\mathrm{C}$ assimilation associated with the low fiber content of low $\mathrm{C}: \mathrm{N}$ food. Conventional wisdom logically interprets the selection of low $\mathrm{C}: \mathrm{N}$ foods by animals as a response to $\mathrm{N}$ limitation. The analysis here indicates that animals would be expected to preferentially select $\mathrm{N}$-rich prey even when limited by $\mathrm{C}$, because the $\mathrm{C}$ in low $\mathrm{C}: \mathrm{N}$ foods is most easily assimilated. Decreasing the efficiency with which assimilated $\mathrm{C}$ is used for growth ( $k_{\mathrm{C}}^{*}$ ) from 0.5 to 0.2 gives rise to predicted C limitation throughout the whole parameter space examined (Fig. 2b). Now, in contrast to Fig. 2a, animals ingesting highly fibrous (high $\mathrm{C}: \mathrm{N}$ ) diets benefit strongly from investing in cellulose-digesting enzymes, whereas animals ingesting low $\mathrm{C}: \mathrm{N}$ food derive little if any such benefit. Two strategies thus emerge if $k_{\mathrm{C}}^{*}$ is low, which give rise to maximal growth rates-fiber eaters that consume high $\mathrm{C}: \mathrm{N}$ food and have efficient fiber digestion, and selective feeders that consume high-quality (low $\mathrm{C}: \mathrm{N}$ ) food but that do not possess fiber-digesting enzymes. These two strategies are well known in ruminants although a third category, opportunistic mixed feeders, also exists (Hofmann 1989). Of course other factors also affect selectivity in grazers, most notably structural anti-quality characteristics including the presence of plant defenses such as spines, awns, burrs, etc. (Laca et al. 2001).

\section{MicronUtrient Stoichiometry}

Limitation by $\mathrm{N}$ is believed to be widespread in the animal kingdom (White 1993). Nitrogen in food is present mostly as amino acids, the building blocks of protein. Many of these amino acids are deemed "essential" because consumers cannot actively synthesize them. Dietary deficiencies in essential amino acids (EAA) can in principle lead to limitation of growth by individual EAA rather than bulk protein (or elemental N). A number of published studies have shown dietary EAA imbalances adversely impacting on growth in various organisms including insects (Briegel 1985, Karowe and Martin 1989), marine zooplankton (Kleppel et al. 1998, Guisande et al. 2000), birds (Peoples et al. 1994, Ramsay and Houston 1998, 2003) and mammals (Lochmiller et al. 1995, van Tets and Hulbert 1999). If EAA in food are imbalanced relative to the demands for protein synthesis, deamination of the excess occurs and part of the $\mathrm{N}$ ration is excreted (Ferguson et al. 1998, Fournier et al. 2003). Various studies have demonstrated correlations between zooplankton production and minor dietary constituents - micronutrients - such as certain amino and fatty acids (Kleppel et al. 1998, Boersma and Stelzer 2000). Reconciling this kind of evidence with the raft of stoichiometric studies indicating element limitation has proved problematic. A good example is provided by freshwater zooplankton, which are widely believed to be limited by elemental phosphorus (Urabe et al. 1997, Elser et al. 2001), but for which there are also numerous studies proposing limitation by essential fatty acids (e.g., Müller-Navarra et al. 2000, see also Boersma 2000).

If shortfalls of particular micronutrients occur in the diet, and the compounds in question cannot be biosynthesized by the consumer, then in principle these biochemicals can be treated in the same (conservative) way as elements. Demand and supply ratios are compared, and the potential limitation by both elements and micronutrients simultaneously evaluated. Such an analysis was carried out by Anderson and Pond (2000), who examined the limiting roles of $\mathrm{C}, \mathrm{N}$, and two essential polyunsaturated fatty acids in the egg production of marine copepods grazing mixtures of two algal groups, diatoms and dinoflagellates. Their analysis indicated that imbalanced diets, and particularly monocultures (which are frequently employed in laboratory experiments), could possess fatty acids in sufficient disproportion to cause direct limitation of egg production. The same principles can be applied to examine the potential for limitation of animal production by individual EAA vs. bulk N. Consider an animal that can potentially utilize $\mathrm{N}$ and EAA with $100 \%$ efficiency when present in limiting amounts in the diet. If that animal consumes a food item in which the ratio of any given EAA to bulk $\mathrm{N}, F_{X: \mathrm{N}}$, is less than that required for growth (specified by the ratio in consumer tissues, $\left.T_{X: \mathrm{N}}\right)$, then that amino acid will in theory become limiting. The resulting reduction in growth, as a ratio to the growth that would occur when limitation is by bulk $\mathrm{N}$, is simply $F_{X: \mathrm{N}} / T_{X: \mathrm{N}}$. Thus for example if a particular EAA is present in food in a ratio half that required by the consumer, then production would be halved due to the imbalance. Multiple EAAs may be deficient in an animal's diet. Using the stoichiometric axiom that a single substrate, the one in least supply relative to demand, is limiting, the extent to which growth is limited by the simultaneous effect of multiple EAAs, the EAA limitation factor, $Y$, is

$$
Y=\min \left(\frac{F_{X 1: \mathrm{N}}}{T_{X 1: \mathrm{N}}}, \frac{F_{X 2: \mathrm{N}}}{T_{X 2: \mathrm{N}}}, \ldots, \frac{F_{X \mathrm{n}: \mathrm{N}}}{T_{X \mathrm{n}: \mathrm{N}}}\right) \quad Y \leq 1
$$

where $n$ is the total number of EAA. A value of $Y=$ 1 would mean that all EAA are present in adequate amounts and limitation is by bulk $\mathrm{N}$.

Published amino acid profiles for a range of animals and typical food items are shown in Fig. 3. In the case of springbok, the body profile of amino acids is compared with the duodenal digesta. Dietary amino acids of ruminants are extensively metabolized by the rumen microorganisms such that the digesta is the best estimate of the supply to the animal. In each case the limiting EAA is identified and resultant $Y$ indicated. The amino acid profiles of the parasitoid wasp, abalone, 

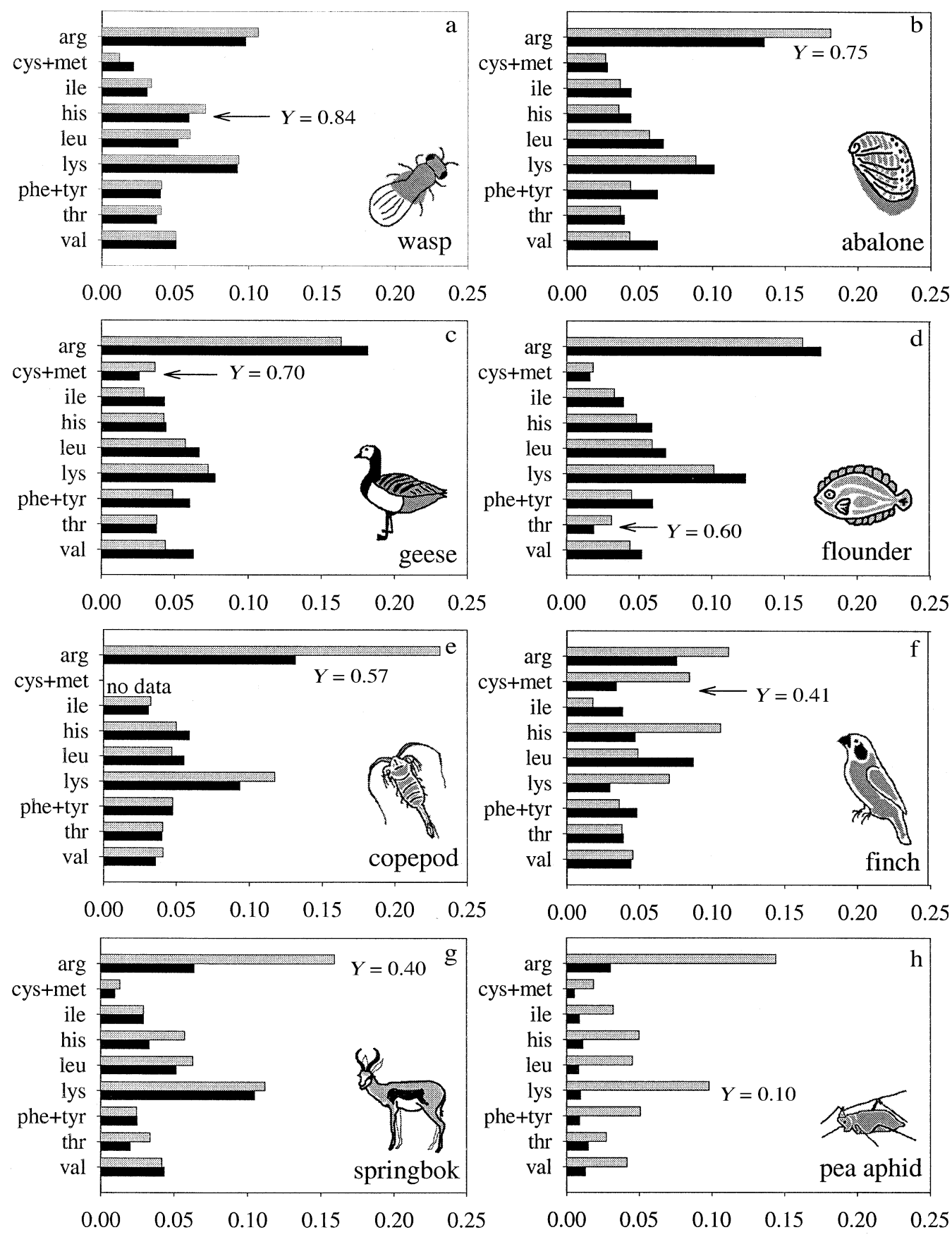

Fraction of total amino acid N

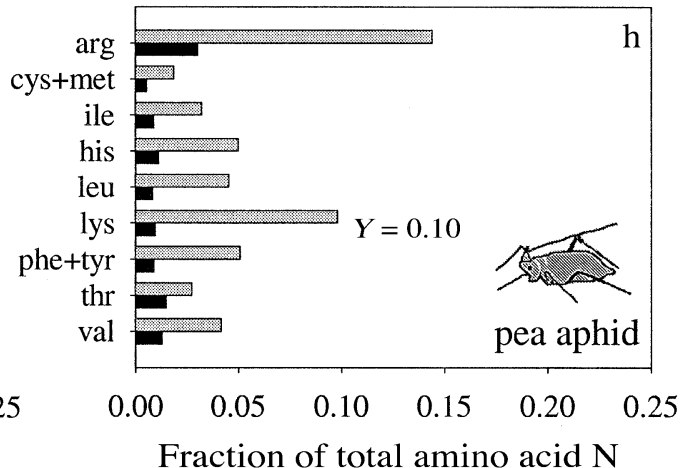

FIG. 3. Comparison of published essential amino acid (EAA) profiles of consumers (light shading) and their food (solid), as fractions of total amino acid $\mathrm{N}$. In each case the limiting EAA is identified, and the corresponding EAA limitation factor $(Y)$ indicated. (a) The egg parasitoid wasp Trichogramma minutum consuming eggs of five lepidopteran hosts (Barrett and Schmidt 1991). (b) Abalone (Haliotis tuberculata L.) consuming a mixture of algal species (Mai et al. 1994). (c) Cackling Geese (Branta canadensis minima) consuming a mixture of arrowgrass and graminoid leaves and seeds (Sedinger 1984). (d) Japanese flounder (Paralichthys olivaceus) fed an experimental diet replicating red sea bream (Pagrus major) egg protein (Alam et al. 2002). (e) Copepods (Euterpina acutifrons) consuming seston (seasonally averaged composition used here) in the Ría de Vigo, Spain (Guisande et al. 2000). (f) Zebra Finches (Poephila guttata) consuming panicum millet seed (Houston et al. 1995a). (g) Springbok (Antidorcas marsupialis): comparison with duodenal digesta (van Zyl and Ferreira 2003). (h) The pea aphid Acyrthosiphon pisum feeding on a diet simulating the phloem sap of alfalfa (Febvay et al. 1999). EAA abbreviations: arg, arginine; cys+met, cysteine plus methionine; ile, isoleucine; hist, histidine; leu, leucine; lys, lysine; phe +tyr, phenylalanine plus tyrosine; thr, threonine; val, valine. 
and geese are relatively well matched with their food, with $Y$ of $0.84,0.75$, and 0.70 , respectively. The flounder is well matched in all EAA except threonine $(Y=$ 0.60 ), and the copepod similarly has a major shortfall in one EAA, arginine $(Y=0.57)$. The finch and particularly the aphid diets are poorly balanced in EAAs relative to consumer requirements, with $Y$ of 0.41 and 0.10 , respectively. Perhaps surprisingly the duodenal digesta of the springbok is apparently deplete in several EAAs, notably arginine $(Y=0.40)$, histidine, and threonine.

Results show that, at least in theory, limitation by EAA rather than by bulk $\mathrm{N}$ may be important in some animals. Two major assumptions underpin the above analysis: the amino acids identified as EAAs truly cannot be synthesized by the consumer or associated symbionts, and the demand ratio of the consumer is inflexible (homeostatic) so that shortages in EAAs render growth impossible. It is generally thought that the ability of animals to synthesize EAAs de novo has disappeared in the course of evolution, and so it has been the convention to divide amino acids into two categories, essential (or indispensable) and nonessential (or dispensable). In recent times the distinction between essential and nonessential amino acids, at least at the metabolic level, is becoming increasingly blurred (Reeds 2000). Amino acids may instead be described as "conditionally" essential, the term being used to imply that there are measurable limitations to the rate at which they can be synthesized. When this limit is reached, the amino acid in question becomes an essential component of the diet. Nevertheless, radiolabeltracer experiments have shown, for prawns and fish, that there are indeed some amino acids required for growth that cannot be synthesized (Cowey et al. 1970, Cowey and Forster 1971). Most evidence suggests that, even in the presence of appropriate precursors, the quantities of conditionally essential EAAs that can be synthesized may be quite limited (see Reeds 2000).

Homeostasis of the consumer, such that it maintains a constant body composition, is an assumption frequently made in stoichiometric studies of aquatic systems. Relatively invariant element ratios are indeed a feature of freshwater and marine zooplankton (Andersen and Hessen 1990, Gismervik 1997), although the fat (and hence C) content of many animals increases with the proportion of extractable carbohydrate in the diet (for an insect example, see Raubenheimer and Simpson [2003]). To what extent are amino acid profiles in animals invariant, thereby fixing dietary requirements for those amino acids that cannot be synthesized? Comparison of the amino acid profiles of the organisms illustrated here (Fig. 3) reveals a general similarity in most instances. Cellular proteins are synthesized based on the genetic information encoded in DNA, and so all else being equal one might expect organisms within a particular taxonomic group to have similar amino acid profiles compared with more dis- tantly related organisms. A basic pattern of amino acid balance has been maintained over evolutionary time, although concentrations of proline (linked to the formation of collagen) and serine (associated with enzyme activity) have generally increased, and alanine, valine, leucine, and isoleucine decreased (Sorimachi 1999, Sorimachi et al. 2000). Various studies have shown only small variability in the EAA composition of animals subjected to variable diets, e.g., parisitoid wasps (Barrett and Schmidt 1991), copepods (Helland et al. 2003), rotifers (Øie and Olsen 1997), prawns (Tidwell et al. 1998), rainbow trout (Yamamoto et al. 2000) and Japanese flounder (Alam et al. 2002). Larger variation in EAA in response to diet has however been observed in other cases, e.g., copepod eggs (Guisande et al. 1999) and tilapia (Gunasekera et al. 1996). On balance, our assumption of homeostasis is probably reasonable, although further work is required to substantiate its validity.

\section{DisCUSSION}

Stoichiometry involves comparing element ratios in consumers and their prey and invoking the element in least supply relative to demand as "limiting". The results presented here show that there are circumstances when the usual application of simple elemental ratios in stoichiometric studies may be inadequate because availability and utilizability are influenced by biochemical aspects of animals' diets. In order to predict how factors such as dietary-fiber content or amino acid composition impact on growth, a knowledge of animal physiology is required.

The first example we present (macronutrient stoichiometry) investigated animal production in response to differing amounts of dietary fiber, quantified in terms of overall food $\mathrm{C}: \mathrm{N}$ ratio. Two herbivore strategies emerge if the efficiency with which assimilated $\mathrm{C}$ is used for growth is low: fiber eaters that consume high $\mathrm{C}: \mathrm{N}$ food and have efficient fiber digestion, and selective feeders which consume high quality (low C:N) food but which do not possess fiber-digesting enzymes. These strategies are both predicted as a means of minimizing limitation by $\mathrm{C}$, not N. Some small mammals may indeed select food in order to maximize energy rather than protein intake (Lewis et al. 2001) because as body size decreases, energy requirements per unit body mass increase at an allometrically greater rate than does gut capacity (Demment and van Soest 1985). Moreover, C assimilated from fibrous sources is thought to significantly contribute to the energy budget of some small animals (Degen et al. 2000).

The analysis suggests that selective feeders may select low $\mathrm{C}: \mathrm{N}$ (N-rich) food not because they require $\mathrm{N}$, but because they are $\mathrm{C}$ limited and $\mathrm{N}$-rich food has associated with it the greatest quantities of readily assimilable $\mathrm{C}$ as a fraction of total C. But is $\mathrm{C}$ limitation real in these animals? One could argue that it is merely a matter of semantics-if an animal's growth is pro- 
portional to the amount of N-rich food ingested then surely it is fair to say that it is $\mathrm{N}$ limited. At face value such an assertion may seem reasonable, but there are good reasons to distinguish between correlation and actual causation. For example, if animals are really limited by $\mathrm{N}$ then imbalances in essential amino acids (EAAs) will potentially directly impact on growth. If however growth is merely correlated with $\mathrm{N}$, then EAA imbalances may have little or no effect because bulk $\mathrm{N}$ is in excess. Such considerations are important when, for example, designing nutrient supplements in agricultural systems. But what of larger animals with lower relative metabolic costs? Is efficient digestion of fibrous $\mathrm{C}$ by ruminants purely a response to $\mathrm{C}$ limitation? The answer is probably not. Even if these animals do not require the $\mathrm{C}$ in fibrous foods, a high fiber-assimilation efficiency may be a requirement simply to be able to reach and digest the high-quality cytoplasmic material within plant cells. It is also used by symbiotic microbes in the rumen to synthesize amino acids by recycling urea, and so ultimately contributes to the animal's requirements for nitrogenous growth-supporting nutrients.

In our second example (micronutrients), significant consumer-food EAA imbalances were demonstrated in several of the animals studied, namely the pea aphid, springbok, zebra finch, copepod, and flounder. Such imbalances should theoretically lead to marked reductions in growth. The aquaculture and farming industries have recognized the potential of supplementing foodstuffs with limiting EAAs in order to maximize growth per unit crude protein supplied, minimizing marginal excesses of nonlimiting amino acids (Ketola 1982, Wu et al. 1997, Kidd et al. 2000). The fact that amino acid imbalances occur in farmed animals is evident in improved yields in response to supplementation. In no instance was bulk protein $\mathrm{N}$ predicted to be limiting in our analysis. It should be noted however that a potential $100 \%$ utilization efficiency for $\mathrm{N}$ was assumed. If the maximum utilization efficiency of bulk $\mathrm{N}$ is lower, and EAA can be spared for growth relative to nonessential amino acids, then the relative availability of EAA for growth is increased and the potential for limitation by bulk $\mathrm{N}$ accordingly increased as well.

In our view the important assumptions that underpin the analysis, namely the consumer being homeostatic with respect to EAA composition and unable to synthesize EAA in significant quantities, may be reasonable, although further research is required. However when assessing the potential of EAA limitation it is necessary to consider physiological adaptations of organisms that improve EAA availability and use. One possibility is the self-selection from complementary foods of balanced diets, which might be possible even where animals do not have specific taste mechanisms for the limiting micronutrients (Simpson and Raubenheimer 1993). Animals might also utilize endogenous sources of amino acids to supplement dietary intake as a source of EAA, particularly during the reproductive season. Many bird species show significant depletion of muscle at the time of egg production, with muscle proteins contributing directly to egg formation (Houston et al. 1995b). Similarly, White-crowned Sparrows were shown to increase their reutilization of EAAs derived from body proteins when transferred from highto low-protein diets (Murphy 1993).

The most dramatic consumer-food mismatch in EAAs in our study was that of the pea aphid, which had an EAA limitation factor $(Y)$ of 0.11 . Pea aphids are nevertheless able to thrive on EAA-deplete sap due to the presence of endosymbiotic bacteria that are able to synthesize all amino acids, especially the essential ones, from sucrose carbon (Febvay et al. 1999, Wilkinson and Ishikawa 2001). The degree to which other animals are supplemented with EAAs by symbionts has been less well studied. Many shallow-water Cnidaria (corals, sea anemones) bear algae that may contribute to the nutrition of their hosts by supplying EAAs, which are translocated to the animal tissues (Fitzgerald and Szmant 1997), as was observed by Wang and Douglas (1999) using radiolabeled-carbon experiments. Symbiotic relationships are common in mammals. Various amino acids are synthesized de novo by the rumen microorganisms (Atasoglu et al. 1999), so that ruminant animals are not necessarily dependent on having a balanced amino acid composition in forages. It is perhaps therefore surprising that the duodenal digesta of the springbok was imbalanced in EAA relative to body tissues (Fig. 3). The gut flora in nonruminant mammals and indeed humans can also be a significant source of microbially derived amino acids (Metges 2000, Torrallardona et al. 2003). These factors, along with the observed efficient recycling of $\mathrm{N}$ by many animals, lend support to the idea that limitation by EAAs can be nullified to the extent that availability of bulk $\mathrm{N}$ is more important. Examples of this recycling include usage of uric acid by endosymbionts in insects (Sasaki et al. 1996), and even drinking urine, which has been suggested as a N-balancing mechanism in redtail monkeys (Lambert 2000).

From a system-dynamics viewpoint it is important to identify limiting factors in order to understand animal utilization efficiencies and cycling of elements in ecosystems (Hessen et al. 2004). From an animal's point of view, however, limitation implies shortage, leading to retardation of growth. Many animals, particularly those utilizing uniformly poor diets, are able to perform compensatory feeding, ingesting large excesses of unwanted substrates in order to obtain the dietary nutrients they require (Cruz-Rivera and Hay 2000, White et al. 2000). Indeed the ability to ingest surplus quantities of excessive nutrients may be an important limitation in some animals (Raubenheimer and Simpson 1997), which are then simply food limited.

The beauty of stoichiometry lies in its simplicity, yet its limitations are exposed by the primitive parameter-

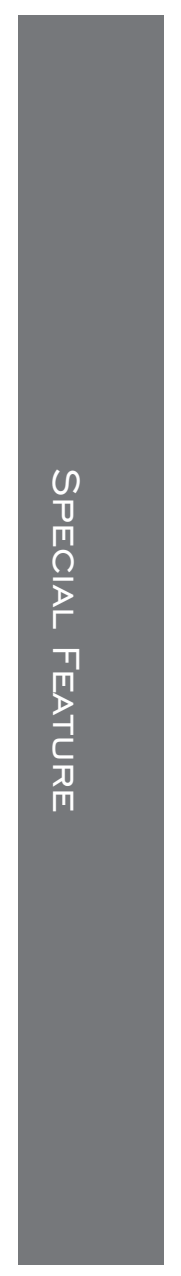


izations involved. There are of course more advanced means of modeling animal production. For example the dynamic energy budget (DEB) approach (Kooijman 1995) provides a theoretical framework that determines the rates at which individual organisms acquire energy and then utilize it for growth, maintenance, and reproduction. As the DEB approach specifies all energy fluxes, it also captures mass fluxes such as the production of $\mathrm{CO}_{2}$ and $\mathrm{N}$ waste. A new concept added to the DEB approach is the "synthesizing unit" (SU), which describes the smooth transitions between states with different dominant limiting factors (Kooijman 1998). Enzymatic processes that handle a wide range of limiting compounds and form one or more products are represented based on probability theory of substrates being attached to binding sites on SUs. One such model was used by Muller et al. (2001) to investigate the effect of algal C:P on the growth dynamics of Daphnia. The analyses presented here have shown that in cases where the utilization efficiencies of elements such as $\mathrm{C}$ and $\mathrm{N}$ are intimately linked to the biochemical forms in which they are present in food-i.e., most of the timethere may be significant violations of the assumptions of ecological stoichiometry. Our work here emphasizes the need to consider the biochemical arguments when studying $\mathrm{C}$ and nutrient transfers in ecosystems, be it using simple stoichiometry or more advanced models such as the DEB approach.

\section{ACKNOWLEDGMENTS}

We wish to thank the European Science Foundation for sponsoring the workshop "Stoichiometric constraints on carbon sequestration in ecosystems" (Oslo 2000), which inspired this work, and Dag Hessen for the organization of the workshop. T.R. Anderson is funded by the Natural Environment Research Council, UK. M. Boersma was partly funded by the European Community and the German Science Foundation. D. Raubenheimer is funded by a BBSRC grant.

\section{LiterATURE Cited}

Alam, M. S., S. Teshima, D. Yaniharto, S. Koshio, and M. Ishikawa. 2002. Influence of different dietary amino acid patterns on growth and body composition of juvenile Japanese flounder, Paralichthys olivaceus. Aquaculture 210: 359-369.

Andersen, T., and D. O. Hessen. 1990. Carbon, nitrogen and phosphorus content of freshwater zooplankton. Limnology and Oceanography 36:807-814.

Anderson, T. R. 1992. Modelling the influence of food C:N ratio, and respiration on growth and nitrogen excretion in marine zooplankton and bacteria. Journal of Plankton Research 14:1645-1671.

Anderson, T. R., and D. O. Hessen. 1995. Carbon or nitrogen limitation in marine copepods? Journal of Plankton Research 17:317-331.

Anderson, T. R., and D. W. Pond. 2000. Stoichiometric theory extended to micronutrients: comparison of the roles of essential fatty acids, carbon, and nitrogen in the nutrition of marine copepods. Limnology and Oceanography 45:11621167.

Atasoglu, C., C. Valdes, C. J. Newbold, and R. J. Wallace. 1999. Influence of peptides and amino acids on fermentation rate and de novo synthesis of amino acids by mixed micro-organisms from the sheep rumen. British Journal of Nutrition 81:307-314.
Barrett, M., and J. M. Schmidt. 1991. A comparison between the amino acid composition of an egg parasitoid wasp and some of its hosts. Entomologia Experimentalis et Applicata 59:29-41.

Boersma, M. 2000. The nutritional quality of phosphorus limited algae for Daphnia. Limnology and Oceanography 45:1157-1161.

Boersma, M., and C. P. Stelzer. 2000. Response of a zooplankton community to the addition of unsaturated fatty acids: an enclosure study. Freshwater Biology 45:179-188.

Briegel, H. 1985. Mosquito reproduction: incomplete utilization of the blood meal protein for oögenesis. Journal of Insect Physiology 31:15-21.

Cowey, C. B., J. W. Adron, and A. Blair. 1970. Studies on the nutrition of marine flatfish. The essential amino acid requirements of plaice and sole. Journal of the Marine Biological Association of the United Kingdom 50:87-95.

Cowey, C. B., and J. R. M. Forster. 1971. The essential amino-acid requirements of the prawn Palaemon serratus. The growth of prawns on diets containing proteins of different amino-acid compositions. Marine Biology 10:77-81.

Cruz-Rivera, E., and M. E. Hay. 2000. Can quantity replace quality? Food choice, compensatory feeding, and fitness of marine mesograzers. Ecology 81:201-219.

Degen, A. A., M. Kam, I. S. Khokhlova, and Y. Zeevi. 2000. Fiber digestion and energy utilization of fat sand rats (Psammomys obesus) consuming the chenopod Anabasis articulata. Physiological and Biochemical Zoology 73: 574-580.

Demment, M. W., and P. J. van Soest. 1985. A nutritional explanation for body-size patterns of ruminant and nonruminant herbivores. American Naturalist 125:641-672.

DeMott, W. R., and R. D. Gulati. 1999. Phosphorus limitation in Daphnia: evidence from a long term study of three hypereutrophic Dutch lakes. Limnology and Oceanography 44:1557-1564.

Elser, J. J., K. Hayakawa, and J. Urabe. 2001. Nutrient limitation reduces food quality for zooplankton: Daphnia response to seston phosphorus enrichment. Ecology 82:898903.

Febvay, G., Y. Rahbé, M. Rynkiewicz, J. Guillaud, and G. Bonnot. 1999. Fate of dietary sucrose and neosynthesis of amino acids in the pea aphid, Acyrthosiphon pisum, reared on different diets. Journal of Experimental Biology 202: 2639-2652.

Ferguson, N. S., R. S. Gates, J. L. Taraba, A. H. Cantor, A. J. Pescatore, M. J. Ford, and D. J. Burnham. 1998. The effect of dietary crude protein on growth, ammonia concentration, and litter composition in broilers. Poultry Science 77:1481-1487.

Fitzgerald, L. M., and A. M. Szmant. 1997. Biosynthesis of 'essential' amino acids by scleractinian corals. Biochemical Journal 322:213-221.

Fournier, V., M. F. Gouillou-Coustans, R. Métailler, C. Vachot, J. Moriceau, H. Le Delliou, C. Huelvan, E. Desbruyeres, and S. J. Kaushik. 2003. Excess dietary arginine affects urea excretion but does not improve $\mathrm{N}$ utilisation in rainbow trout Oncorhynchus mykiss and turbot Psetta maxima. Aquaculture 217:559-576.

Gismervik, I. 1997. Stoichiometry of some marine planktonic crustaceans. Journal of Plankton Research 19:279-285.

Guisande, C., I. Maneiro, and I. Riveiro. 1999. Homeostasis in the essential amino acid composition of the marine copepod Euterpina acutifrons. Limnology and Oceanography 44:691-696.

Guisande, C., I. Riveiro, and I. Maneiro. 2000. Comparisons among the amino acid composition of females, eggs and food to determine the relative importance of food quantity and food quality to copepod reproduction. Marine Ecology Progress Series 202:135-142. 
Gunasekera, R. M., K. F. Shim, and T. J. Lam. 1996. Effect of dietary protein level on spawning performance and amino acid composition of eggs of Nile tilapia, Oreochromis niloticus. Aquaculture 146:121-134.

Helland, S., J. C. Nejstgaard, R. Humlen, H. J. Fyhn, and U. Båmstedt. 2003. Effects of season and maternal food on Calanus finmarchicus reproduction, with emphasis on free amino acids. Marine Biology 142:1141-1151.

Hessen, D. O., G. I. Ågren, T. R. Anderson, J. J. Elser, and P. De Reuter. 2004. Carbon sequestration in ecosystems: the role of stoichiometry. Ecology 85:1179-1192.

Hofmann, R. R. 1989. Evolutionary steps of ecophysiological adaptation and diversification of ruminants: a comparative view of their digestive system. Oecologia 78:443-457.

Houston, D. C., D. Donnan, and P. J. Jones. 1995a. The source of the nutrients required for egg production in zebra finches Poephila guttata. Journal of Zoology 235:469-483.

Houston, D. C., D. Donnan, P. J. Jones, I. D. Hamilton, and D. Osborne. 1995 b. Changes in the muscle condition of female zebra finches during egg laying and the role of protein storage in bird skeletal muscle. Ibis 137:322-329.

Karowe, D. N., and M. M. Martin. 1989. The effects of quantity and quality of diet nitrogen on the growth, efficiency of food utilization, nitrogen budget, and metabolic rate of fifth-instar Spodoptera eridania larvae (Lepidoptera: Noctuidae). Journal of Insect Physiology 35:699-708.

Ketola, G. H. 1982. Amino acid nutrition of fishes: requirements and supplementation of diets. Comparative Biochemistry and Physiology B 73:17-24.

Kidd, M. T., B. J. Kerr, J. P. Allard, S. K. Rao, and J. T. Halley. 2000. Limiting amino acid responses in commercial broilers. Journal of Applied Poultry Research 9:223233.

Kiørboe, T. 1989. Phytoplankton growth rate and nitrogen content: implications for feeding and fecundity in a herbivorous copepod. Marine Ecology Progress Series 55: $229-234$

Kleppel, G. S., C. A. Burkart, and L. Houchin. 1998. Nutrition and the regulation of egg production in the calanoid copepod Acartia tonsa. Limnology and Oceanography 43: 1000-1007.

Kooijman, S. A. L. M. 1995. The stoichiometry of animal energetics. Journal of Theoretical Biology 177:139-149.

Kooijman, S. A. L. M. 1998. The synthesizing unit as a model for stoichiometric fusion and branching of metabolic fluxes. Biophysical Chemistry 73:179-188.

Laca, E. A., L. A. Shipley, and E. D. Reid. 2001. Structural anti-quality characteristics of range and pasture plants. Journal of Range Management 54:413-419.

Lambert, J. E. 2000. Urine drinking in wild Cercopithecus ascanius: evidence of nitrogen balancing? African Journal of Ecology 38:360-362.

Lewis, C. E., T. W. Clark, and T. L. Derting. 2001. Food selection by the white-footed mouse (Peromyscus leucopus) on the basis of energy and protein contents. Canadian Journal of Zoology 79:562-568.

Lochmiller, R. L., D. G. Peitz, D. M. Leslie, and D. M. Engle. 1995. Habitat-induced changes in essential amino-acid nutrition in populations of eastern cottontails. Journal of Mammalogy 76:1164-1177.

Mai, K., J. P. Mercer, and J. Donlon. 1994. Comparative studies on the nutrition of two species of abalone, Haliotis tuberculata L. and Haliotis discus hannai Ino. II. Amino acid composition of abalone and six species of macroalgae with an assessment of their nutritional value. Aquaculture 128: $115-130$.

Metges, C. C. 2000. Contribution of microbial amino acids to amino acid homeostasis of the host. Journal of Nutrition 130: $1857 \mathrm{~S}-1864 \mathrm{~S}$.
Muller, E. B., R. M. Nisbet, S. A. L. M. Kooijman, J. J. Elser, and E. McCauley. 2001. Stoichiometric food quality and herbivore dynamics. Ecology Letters 4:519-529.

Müller-Navarra, D. C., M. T. Brett, A. M. Liston, and C. R. Goldman. 2000. A highly unsaturated fatty acid predicts carbon transfer between primary producers and consumers. Nature 403:74-77.

Murphy, M. E. 1993. The protein requirement for maintenance in the white-crowned sparrow, Zonotrichia leucophrys gambelii. Canadian Journal of Zoology 71:21112120.

Niemann, G. J., J. B. M. Pureveen, G. B. Eijkel, H. Poorter, and J. J. Boon. 1992. Differences in relative growth rate in 11 grasses correlate with differences in chemical composition as determined by pyrolysis mass spectrometry. Oecologia 89:567-573.

Øie, G., and Y. Olsen. 1997. Protein and lipid content of the rotifer Brachionus plicatilis during variable growth and feeding condition. Hydrobiologia 358:251-258.

Peoples, A. D., R. L. Lochmiller, D. M. Leslie, J. C. Boren, and D. M. Engle. 1994. Essential amino acids in Northern Bobwhite foods. Journal of Wildlife Management 58:167175.

Plath, K., and M. Boersma. 2001. Mineral limitation of zooplankton: stoichiometric constraints and optimal foraging. Ecology 82:1260-1269.

Poorter, H., and M. Bergkotte. 1992. Chemical composition of 24 wild species differing in relative growth rate. Plant, Cell and Environment 15:221-229.

Ramsay, S. L., and D. C. Houston. 1998. The effect of dietary amino acid composition on egg production in blue tits. Proceedings of the Royal Society Series B 265:1401-1405.

Ramsay, S. L., and D. C. Houston. 2003. Amino acid composition of some woodland arthropods and their implications for breeding tits and other passerines. Ibis 145:227232 .

Raubenheimer, D., and S. J. Simpson. 1997. Integrative models of nutrient balancing: application to insects and vertebrates. Nutrition Research Reviews 10:151-179.

Raubenheimer, D., and S. J. Simpson. 1998. Nutrient transfer functions: the site of integration between feeding behaviour and nutritional physiology. Chemoecology 8:61-68.

Raubenheimer, D., and S. J. Simpson. 2003. Nutrient balancing in grasshoppers: behavioural and physiological correlates of dietary breadth. Journal of Experimental Biology 206: $1669-1681$.

Reeds, P. J. 2000. Dispensable and indispensable amino acids for humans. Journal of Nutrition 130:1835S-1840S.

Roman, M. R. 1983. Nitrogenous nutrition of marine invertebrates. Pages 347-383 in E. J. Carpenter and D. G. Capone, editors. Nitrogen in the marine environment. Academic Press, London, UK.

Sasaki, T., M. Kawamura, and H. Ishikawa. 1996. Nitrogen recycling in the brown planthopper, Nilaparvata lugens: involvement of yeast-like endosymbionts in uric acid metabolism. Journal of Insect Physiology 42:125-129.

Schroeder, L. A. 1981. Consumer growth efficiencies: their limits and relationships to ecological energetics. Journal of Theoretical Biology 93:805-828.

Sedinger, J. S. 1984. Protein and amino acid composition of tundra vegetation in relation to nutritional requirements of geese. Journal of Wildlife Management 48:1128-1136.

Simpson, S. J., and D. Raubenheimer. 1993. The central role of the haemolymph in the regulation of nutrient intake in insects. Physiological Entomology 18:395-403.

Slansky, F., and P. Feeny. 1977. Stabilization of the rate of nitrogen accumulation by larvae of the cabbage butterfly on wild and cultivated food plants. Ecological Monographs 47:209-228.

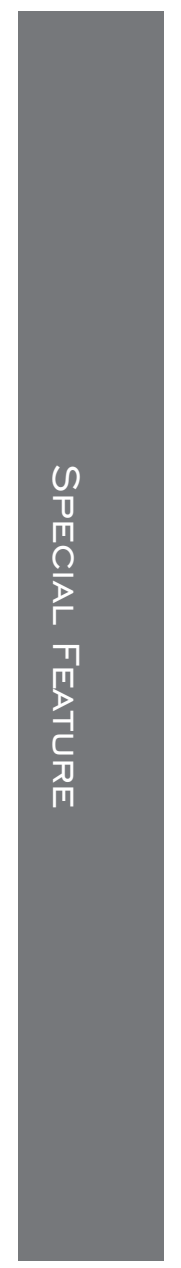


Sorimachi, K. 1999. Evolutionary changes reflected by the cellular amino acid composition. Amino Acids 17:207226.

Sorimachi, K., T. Okayasu, K. Akimoto, and A. Niwa. 2000. Conservation of the basic pattern of cellular amino acid composition during biological evolution in plants. Amino Acids 18:193-197.

Taylor, B. R., D. Parkinson, and W. F. J. Parsons. 1989. Nitrogen and lignin content as predictors of litter decay rates: a microcosm test. Ecology 70:97-104.

Thompson, S. N. 1998. Long-term regulation of glucogenesis by dietary carbohydrate and relevance to blood sugar level in an insect Manduca sexta L. International Journal of Biochemistry and Cell Biology 30:987-999.

Tidwell, J. H., C. D. Webster, S. D. Coyle, W. H. Daniels, and L. R. D'Abramo. 1998. Fatty acid and amino acid composition of eggs, muscle and midgut glands of freshwater prawns, Macrobrachium rosenbergii (de Man), raised in fertilized ponds, unfertilized ponds or fed prepared diets. Aquaculture Research 29:37-45.

Torrallardona, D., C. I. Harris, and M. F. Fuller. 2003. Pigs' gastrointestinal microflora provide them with essential amino acids. Journal of Nutrition 133:1127-1131.

Urabe, J., J. Clasen, and R. W. Sterner. 1997. Phosphorus limitation of Daphnia growth: is it real? Limnology and Oceanography 42:1436-1443.

Urabe, J., and Y. Watanabe. 1992. Possibility of N or P limitation for planktonic cladocerans: an experimental test. Limnology and Oceanography 37:244-251. composition and anatomical structure of leaves of grass species differing in relative growth rate. Plant, Cell and Environment 17:963-970.

van Tets, I. G., and A. J. Hulbert. 1999. A comparison of the nitrogen requirements of the eastern pygmy possum, Cercartetus nanus, on a pollen and on a mealworm diet. Physiological and Biochemical Zoology 72:127-137. van Zyl, L., and A. V. Ferreira. 2003. Amino acid requirements of springbok (Antidorcas marsupialis), blesbok (Damaliscus dorcas phillipsi) and impala (Aepyceros melampus) estimated by the whole empty body essential amino acid profile. Small Ruminant Research 47:145-153.

Wang, J. T., and A. E. Douglas. 1999. Essential amino acid synthesis and nitrogen recycling in an alga-invertebrate symbiosis. Marine Biology 135:219-222.

White, B. D., M. H. Porter, and R. J. Martin. 2000. Protein selection, food intake, and body composition in response to the amount of dietary protein. Physiology and Behaviour 69:383-389.

White, T. C. R. 1984. The abundance of invertebrate herbivores in relation to the availability of nitrogen in stressed food plants. Oecologia 63:90-105.

White, T. C. R. 1993. The inadequate environment: nitrogen and the abundance of animals. Springer-Verlag, New York, New York, USA.

Wilkinson, T. L., and H. Ishikawa. 2001. On the functional significance of symbiotic microorganisms in the Homoptera: a comparative study of Acyrthosiphon pisum and $\mathrm{Ni}$ laparvata lugens. Physiological Entomology 26:86-93.

Wu, Z., C. E. Polan, and R. J. Fisher. 1997. Adequacy of amino acids in diets fed to lactating dairy cows. Journal of Dairy Science 80:1713-1721.

Yamamoto, T., T. Unuma, and T. Akiyama. 2000. The influence of dietary protein on tissue free amino acid levels of fingerling rainbow trout (Oncorhynchus mykiss). Aquaculture 182:353-372.

Zanotto, F. P., S. M. Gouveia, S. J. Simpson, D. Raubenheimer, and P. C. Calder. 1997. Nutritional homeostasis in locusts: is there a mechanism for increased energy expenditure during carbohydrate overfeeding? Journal of Experimental Biology 200:2473-2448.

Zanotto, F. P., S. J. Simpson, and D. Raubenheimer. 1993. The regulation of growth by locusts through post-ingestive compensation for variation in the levels of dietary protein and carbohydrate. Physiological Entomology 18:425-434. 